\title{
VIAJANTES DO SÉCULO XIX: UMA REFLEXÃO SOBRE AS ESTÉTICAS DO PITORESCO E DO SUBLIME NA CONSTRUÇÃO DE REPRESENTAÇÕES PARA O BRASIL
}

Patrícia Vargas Lopes de Araujo ${ }^{1}$

\section{Resumo}

Tem-se como objetivo elaborar uma discussão acerca da imagem ou imagens do Brasil em fins do século XVIII e primeira metade do século XIX. Ainda, analisar quais imagens os europeus faziam do Brasil e pensar como no próprio território brasileiro se articulava ou se compartilhava das idéias circulantes no velho mundo. Por outro lado, compreender o papel ou importância dos viajantes face à elaboração e difusão de noções sobre Brasil e a sociedade brasileira, a partir de uma possível chave de entendimento que seriam, além das perspectivas políticas, as concepções estéticas do pitoresco e do sublime.

Palavras-chave: pitoresco, sublime, Brasil

\begin{abstract}
It had as objective to elaborate a discussion about the image or images from Brazil at the end of XVIII ${ }^{\text {th }}$ century and the first half of XIX ${ }^{\text {th }}$ century. Yet, to analyze which images the Europeans had of Brazil and to think how the owm Brazilian territory was articulated or if it was shared of the circulating ideas in the old world. On the other hand, to understand the paper or importance of the travellers face to the elaboration and diffusion of slight knowledge about Brazil and Brazilian society, through a possible key of understanding that would be, besides the politics perspectives, the aesthetic conceptions of the picturesque and the sublime.
\end{abstract}

Keywords: picturesque, sublime, Brazil

Procuro aqui elaborar uma discussão, ainda preliminar e aberta, acerca da imagem ou imagens do Brasil em fins do século XVIII e primeira metade do século XIX. Ou ainda, quais imagens se faziam do Brasil na Europa e como no próprio Brasil se articulava ou se compartilhava das idéias circulantes no velho mundo. Por outro lado, compreender o papel ou importância dos viajantes face à elaboração e difusão de noções sobre Brasil, particularmente quanto a relações estabelecidas entre a dimensão política e a estética.

Certamente os chamados "viajantes" foram extremamente importantes na elaboração da idéia de Brasil na Europa e contribuíram para a elaboração e para a fixação de imagens sobre a sociedade brasileira. Estes têm sido, dessa maneira, convocados a dar conta, com seus depoimentos e relatos, de uma parte significativa de nosso passado.

Parte expressiva das representações sobre o Brasil, particularmente no século XIX, foi elaborada no contexto de viagens por autores que tomavam como seu objetivo construir relatos capazes de transmitir a outrem as experiências vividas em terras pouco acessíveis e ainda desconhecidas (LEITE, 1996: 38).

As motivações para as viagens são as mais variadas, sendo também uma realidade comum a diferentes culturas em todas as épocas da história. As circunstâncias que impelem às viagens são de múltipla ordem: quebra da rotina e do cotidiano, busca da aventura, conquista

1 Doutorado em História, IFCH/UNICAMP 
de riquezas, fuga da miséria, atração pelo imaginário, pelo maravilhoso, busca do exótico e da alteridade, desejo de propagar a fé, de realização de peregrinação religiosa, inspiração literária e a curiosidade científica (LOBO, 1998:1991).

De um modo geral, as viagens, da Antigüidade até os séculos XIV e XV, representaram sobretudo uma aventura individual ou de pequenos grupos, desafiando os obstáculos e as grandes dificuldades. Em fins do século XIV e início do século XV é possível notar mudanças com relação ao ideário da antiguidade e da época medieval. A aventura individual ou de grupos sede lugar às expedições baseadas em capitais particulares e/ou estatais. Além disso, na transição entre a época medieval e o período moderno, ocorre uma ruptura tanto com relação à incorporação da "idéia de errância medieval dos referenciais de busca de riquezas e lucros quanto pela afirmação de uma nova relação entre o europeu e os habitantes do restante do mundo", estabelecendo-se a estruturação de uma visão subjetiva e etnocêntrica que será marcante nos séculos seguintes (SILVA, 2003:51-52).

É preciso registrar também que prevaleceu durante todo este período à idéia de busca do maravilhoso, ou seja, do distante e do desconhecido, sendo predominantes, tanto para o homem quanto para a natureza, características imaginárias, fantásticas e também a incorporação de mitos relacionados ao paraíso, ao éden, ao eldorado e à terra prometida. Para alguns autores, o maravilhoso ou a busca do maravilhoso, declinaria nos séculos XVII e XVIII devido à ampliação do conhecimento e do contato com a realidade. Outros, como é o caso de Eulália Lobo, acreditam que nestes séculos o maravilhoso assume novas formas. A desvinculação com o fantástico e com o onírico, nos escritos de viagens não ocorreu completamente, podendo se afirmar que existiram entre o século XVI e XIX diversos relatos que mesclaram fantasia e realidade (SILVA, 2003:167).

De todo modo, vê-se a partir do período moderno a constituição de uma "nova cultura", na qual uma "visão antropocêntrica e cosmopolita" ganha espaço frente ao imaginário fabuloso e mítico medieval e transforma a "curiosidade diletante em busca do conhecimento, o empírico em experimental e os dogmas em teorias e hipóteses" (SILVA, 2003:52).

Falar sobre é tornar real, e o discurso dos viajantes é um esforço de dar realidade e inteligibilidade ao que se vê através de uma espessa camada de representações, em que versões são superpostas a fatos, evidenciando como as culturas estabelecem identidades e alteridade, aproximações e afastamentos, hierarquias e desordens (SILVA, 2003:54).

Os relatos de viagem não são portadores apenas de descrições de lugares exóticos ou de costumes estranhos, mas acabam por representar uma certa amálgama entre dois mundos, que possibilita ao pensamento humano se organizar e apreender as diferenças e as similitudes.

O olhar europeu, ao longo dos séculos, estrutura-se objetivamente na observação e no relato das especificidades das terras longínquas, inventariando e inventando, tornando o distante, o exótico e o diferente algo possível de ser imaginado e decifrado em seu sentido e utilidade (SILVA, 2003:56).

No caso do Brasil, os olhares dos viajantes revelam certas permanências verificadas em textos de línguas e sensibilidades distintas, como também de épocas diferentes. Elementos de teor idílico, como formosura e fertilidade da terra, aspecto e afabilidade da população, como 
também questões relacionadas à novidade e estranheza dos costumes, à religiosidade e à expectativa com a economia, estão presentes nos primeiros escritos no século XVI, como por exemplo, em " $A$ carta de Caminha" e em cronistas dos séculos seguintes.

Os textos de viagens, sobre o Brasil, mesmo que em séculos e provenientes de olhares estrangeiros diferentes, revelam tópicos idênticos na apreensão do mundo natural e do homem, e uma percepção de natureza feita pelo deslumbramento do olhar, pela estética, surpresa ou medo, mas que, na sua formulação verbal, apresenta-se condicionado pela expressão de realidade culturais próximas e familiares, que fundamentam constantes pontos de comparação entre o novo e o conhecido (SILVA, 2003:71).

Mas é preciso notar as diferenças entre as primeiras narrativas de cunho edênico e as visões marcadas pelo racionalismo e pelo empirismo dos viajantes que se aventurariam nas "viagens pitorescas" pelo interior do Brasil. O discurso do viajante do século XVI será marcado por referenciais renascentistas, no qual se podem perceber o esforço de estruturação de uma "História Natural", a apreensão de imagens e o estabelecimento de relações de semelhança e contigüidade entre estas fundamentadas por analogias e aproximações.

Se as descobertas no século XVI estavam imbuídas do clima cruzadístico, com a difusão da fé cristã e a conversão dos não-cristãos, os séculos XVII e XVIII estão envolvidos em um projeto iluminista que, (...), transforma o homem europeu em sujeito e o homem selvagem em objeto (SILVA, 2003: 166).

De acordo com Olivério Pinto, excetuando-se a viagem de Charles-Marie de la Condomine (1742/1743) ao longo do rio Amazonas, seria difícil encontrar "qualquer vestígio do Brasil na batalha travada pelo homem, em seu esforço para afastar o véu sob o qual se esconde a Natureza os seus Segredos". (PINTO, 1985: 161). Sobre este fato deve-se considerar ainda a cultura que imperava na metrópole portuguesa. Os conhecimentos seriam tributários da religião e da política adotada por Portugal com relação à colônia, ou seja, a de manter a Colônia fechada à curiosidade de outros povos.

Nos primeiros séculos da expansão marítima e das descobertas, os países envolvidos nesses empreendimentos não possuíam em corpo científico organizado, capaz de empreender estudos acerca das terras descobertas. O próprio caráter predatório, assumido nos primeiros séculos, dispensou esse tipo de investimento por parte dos colonizadores (LEITE,1996: 39).

Durante o período colonial, a produção literária e artística construiu representações relativas aos nativos, as riquezas naturais e as terras, destacando-se deste modo, um conjunto de imagens remetidas a um conteúdo vinculado à visão colonialista e etnocêntrica. Este período caracteriza-se por um pequeno número de estudos e pesquisa acerca do Brasil. A política exclusivista adotada por Portugal foi responsável, no final do século XVIII, da expulsão do cientista alemão Alexander von Humboldt cuja expedição seria considerada suspeita e prejudicial aos interesses políticos do Reino (LEITE, 1996: 41). Entre o século XVI até início do século XIX, as explorações científicas, quando haviam, foram motivadas por disputas em torno da posse e ocupação da terra.

Em fins do século XVIII, iniciam-se as expedições científicas propriamente ditas, agora patrocinadas por Portugal. $O$ interesse pelas expedições científicas foi tardio entre os 
portugueses e estiveram voltadas para a investigação das riquezas naturais, que revelam, portanto, a preocupação com a exploração do território. Desta fase, pode-se destacar os nomes de Alexandre Rodrigues Ferreira e Friedrich Sieber. Conhecer o país percorrendo-o, registrar sua paisagem e suas tradições torna-se uma tarefa não apenas dos estrangeiros que a visitam e elaboram representações sobre Brasil, mas também de escritores e pesquisadores da terra.

Após a transferência da Corte Portuguesa e a abertura dos portos, iniciam-se as expedições científicas patrocinadas também por outras nações. Diferentemente dos séculos anteriores, o século XIX conhecerá um grande afluxo de estrangeiros para terras brasileiras. A expansão mercantilista dos países europeus, a importância dada ao conhecimento das ciências e o interesse por outras culturas motivou inúmeras viagens pelo mundo.

O Brasil, país de vasto território em grande parte desconhecido - posto que fora mantido fechado por séculos pelas políticas protecionistas da coroa portuguesa -, tornou-se simultaneamente destino dessas viagens e alvo dos interesses comerciais e científicos de uma Europa sequiosa pelo desconhecido (MARTINS, 2000:1).

O culto "ao outro" exercia grande fascínio entre os intelectuais europeus e os "países exóticos, como eram então chamadas às colônias, exerciam uma enorme atração" (LEITE, 1997: 9). O Brasil era, como muitas outras colônias e países, procurado por colocar em questão o estranhamento e o desconhecido perante o viajante. Os temas relatados tiveram freqüentemente como critério de escolha fatos considerados "exóticos". Sempre que possível eles procuraram evidenciar as diferenças entre seus países de origem e o Brasil.

Desta maneira, é fácil perceber que as relações estabelecidas entre viajantes e brasileiras, - e o que estava por ser desvendado - eram desiguais. $\mathrm{Na}$ "qualidade de estrangeiro", esse viajante transformava-se em observador privilegiado e atento aos "aspectos, incoerências e contradições da vida cotidiana que os habitantes, ao dá-la como natural e permanente, encontravam-se incapazes de perceber (LEITE, 1996: 60)". Por outro lado, o viajante chegava ao Brasil portador de muitos preconceitos, munido da idéia de ser a imagem da "civilização" diante de um "povo atrasado". Tal postura agravava-se quando se viam frente a obstáculos lingüísticos, culturais e econômicos. Na tentativa de compreensão dos grupos visitados, foram responsáveis por estereótipos que vigoraram por todo século XIX.

A utilização dos relatos e das pinturas destes "estrangeiros" não deve perder de vista que seus registros são portadores de valores, preconceitos, assim como de uma visão idealizada sobre os trópicos, muitas vezes diferente da realidade a ser explorada. É necessário "desconfiar das pistas viciadas que esses viajantes possam ter deixado" (SCHWARCZ, 1999: 12). Mas, se a incompreensão e o estranhamento diante de uma cultura diversa da sua os fizeram descaracterizar em muitas situações os costumes brasileiros, tornaram-lhes, por outro lado, extremamente detalhistas em suas descrições, fazendo de seus relatos preciosas fontes de informação. Vale notar que há presente nas narrativas dos viajantes descrições de caráter pictórico, como detalhes, tons, unidade cromática, indicações de coloração, dobras e volumes. A presença desses elementos aponta para cenas construídas com a finalidade de efeitos plásticos. Tal questão indica a existência de um olhar de paisagista por parte destes estrangeiros. E mais, isso seria indicativo de uma formação intelectual que demonstra o conhecimento de conceitos e padrões estéticos que conformariam o ato de composição artística, seja ela uma pintura ou a escrita. 
A partir de 1808, com a presença da Corte, o Brasil passou por significativas mudanças. O grande afluxo de estrangeiros no início do século XIX provocou também a penetração de idéias. A distância com a Europa diminui e agora interessava à Metrópole revestir a colônia de um caráter cosmopolita. Além disso, tornava necessário também criar e estabelecer condições de infra-estrutura. A Inglaterra, dentre todos os países que se interessaram em manter relações com o Brasil, foi aquele que para cá afluiu após a abertura dos portos. Seria também o primeiro país a conseguir certos privilégios frente aos demais devido a sua participação na transferência da Corte portuguesa para a Colônia quando da invasão das tropas napoleônicas em Lisboa. Os ingleses marcariam a vida brasileira em todas as esferas, inclusive a vida intelectual.

Um dos temas que predominará entre os viajantes do século XIX será o da paisagem. Com a instalação da Corte no Rio de Janeiro e especialmente depois da independência aportam ao país "artistas profissionais" ou não, com amplo manejo do desenho. Tanto artistas como viajantes comuns que aqui chegavam eram educados em uma visão estética do pitoresco. De acordo com Ana Maria Belluzzo,

mais do que a descrição naturalista, predominam entre eles a abordagem romântica do passeio pelos arredores e pelos jardins, a visão do homem 'original' na floresta virgem ou a forte sensação da grandiosidade do universo (BELUZZO, 1996: 18).

$\mathrm{Na}$ linguagem estética do pitoresco ressalta os traços românticos, subjetivos e as sensações. Destacam-se em termos de composição a arte dos jardins, a pintura de paisagens e a literatura romântica. Nas composições aparecem figuras mitológicas, místicas, imagens campestres, o elemento bucólico, animais, aspectos da natureza, as cores e a luminosidade.

No século XIX as representações são construídas face à tensão entre as concepções cientificistas e românticas do conhecimento do mundo. Tais elementos estão presentes na produção literária e artística dos viajantes de formação variadas. A apreensão intelectual do Brasil e a construção de uma narrativa sobre sua história estavam vinculadas à aproximação ou distanciamento da natureza ou da civilização. A natureza permeou todas as concepções de América e de Brasil desde o século XVI, adquirindo grande relevância para pensar sua representação e sua incorporação ao conhecimento da época.

Brasileiros e estrangeiros portadores de olhares e teorias sobre a natureza e os homens, vendo-os e analisando-os, tanto de pontos de vista estéticos como científicos. O conhecimento que a respeito do Brasil se produziu foi parte, portanto, desse amplo e complexo processo de incorporação da América ao conhecimento já estabelecido da natureza e dos homens. As inúmeras e variadas leituras que a seu respeito se fez estiveram vinculadas a uma classificação e hierarquização, tanto da natureza como, e principalmente, dos diferentes grupos humanos e povos (NAXARA, 2000)

Nota-se nestas representações que o caráter positivo da natureza tropical e múltipla consolida-se, tornando-se uma imagem poderosa: a de uma natureza excessiva e provedora, "em meio à qual o homem se perde, tornando-se minúsculo e impotente". A natureza é tomada como objeto para a pesquisa científica e como inspiração artística, provocando sensações e ações tanto positivas quanto negativas, confortantes ou não, para aqueles que a observam.

Nem tudo é simplesmente belo na natureza. Frente a certos espetáculos ou circunstâncias, que apesar de não ameaçar os viajantes diretamente, os colocavam, contudo, 
frente à sua fragilidade, fazendo com que experimentassem de modo paradoxal um prazer indireto ou negativo: o sublime. Como exemplo, o impacto causado pela visão das serras e rochedos pintados por Rugendas, que ao desarmar-lhes a observação traduz um momento singular no registro da paisagem.

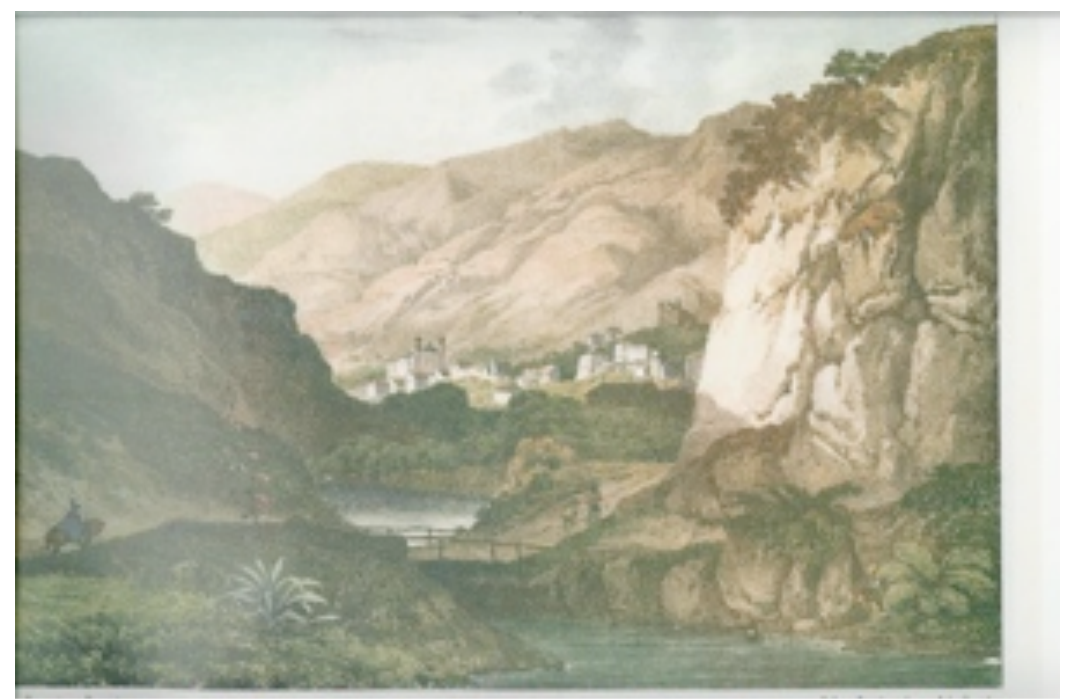

Vila Rica. Johan M. Rugendas. Viagem Pitoresca atrav's do Brasil.

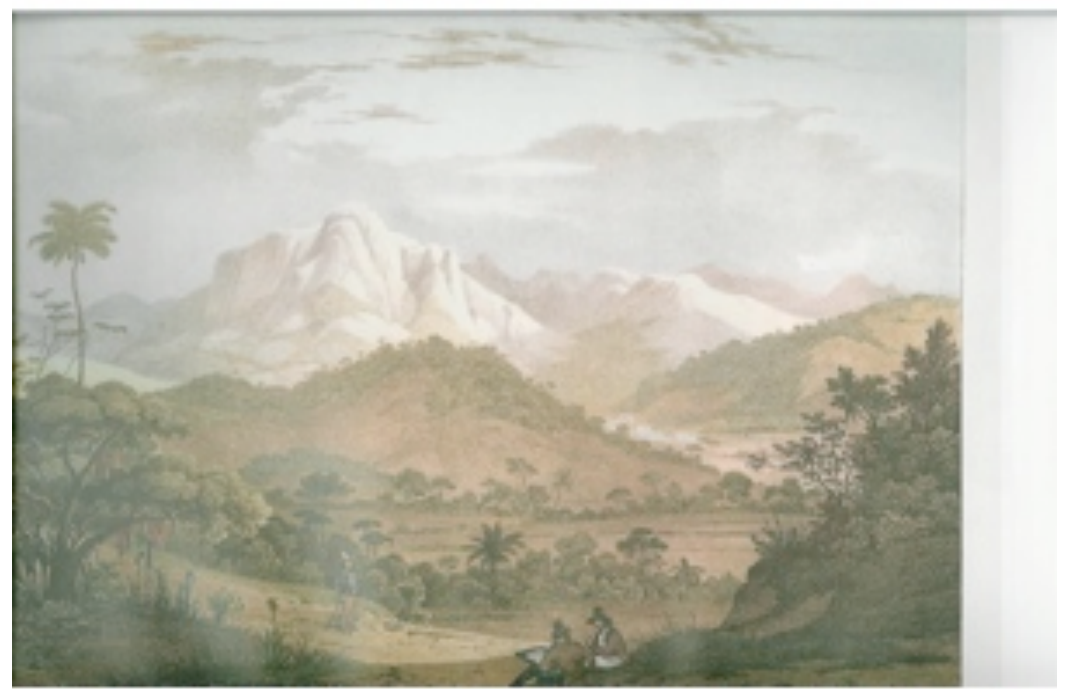

Mandioca. Johan M. Rugendas. Viagem Pitoresca através do Brasil

O sublime produziria no indivíduo primeiro o sentimento de uma suspensão das forças vitais, que violentaria, de certo modo, a imaginação. Dentre os que se dedicaram a fazer al discussão no século XVIII e que influenciaram as perspectivas estéticas ainda no século XIX, pode-se destacar os estudos de Edmund Burke, "Uma investigação filosófica sobre a origem de nossas idéias do sublime e do belo" (1757), que influenciariam posteriormente as discussões de Emmanuel 
Kant sobre o conceito de sublime, efetuadas em "Observações sobre o sentimento do belo e do sublime" (1764) e na "Crítica da Faculdade do Juízo" (1790).

Em Kant "essa violência que ultrapassa as formas sensíveis a ponto de romper os limites, todavia remete-nos a nós mesmos: às Idéias da razão que levam a um mundo suprasensível, que nunca pode ser conhecido" (RIBON, 19991:34). A fonte do sublime está no próprio indivíduo, que tem a capacidade de diante da natureza "absolutamente imensa" e "infinitamente poderosa" ver despertar a sua força interior de resistir

não apenas à onipotência da natureza mas à nossa própria natureza sensível, à força de nossas inclinações que, de maneira imperiosa, deve dominar a lei moral racional, a qual, por ser interior, faz nossa eminente dignidade. Descobrir no sublime que podemos nos determinar não conforme a busca do prazer, da felicidade ou o instinto de conservação mas conforme a representação da lei moral em nós. A grandeza do sublime opera então, num sentimento exaltado, a síntese da consciência que temos da necessidade e do orgulho de nossa liberdade (RIBON, 1991:34).

Quanto à imagem do Brasil continuava a se apresentar ao exterior uma idéia de "terra encantada" portadora de riquezas naturais, com belo clima, rios, flores e animais, e também a decepção com o atraso e a perspectiva do progresso. Deste modo, o índio e a natureza constituíam o foco principal das atenções. Agora, entretanto, fazendo parte de estudos sistemáticos e classificatórios. A idéia de progresso tão presente na Europa reforçava sua imagem e em contrapartida deformava o Outro pela comparação (LEITE, 1996: 48).

Sobressai, por todo o século XIX, uma preocupação com a civilização e com o progresso, cujos modelos eram fornecidos pela Europa. Por outro lado, outros costumes conflitantes com as perspectivas civilizadoras das elites eram progressivamente combatidos e considerados "bárbaros" e "selvagens". Da Europa, partia várias projeções do que se compreendia e se desejava como significado da civilização. No Brasil, desejava-se não apenas um outro lugar diferente, mas um outro lugar melhor, isto é, o mundo europeu, o mundo civilizado. Subjacente a este sentimento estava à idéia de que a história do mundo ocidental é portadora de um conjunto de características às quais se atribui o nome de civilização, que torna o conceito ao mesmo tempo includente e excludente (NAXARA, 2000).

Para Naxara, a idéia da formação da nação estava ligada à construção de uma imagem a ser buscada e perseguida, "imagem estética, plasticamente dimensionada, que contém em si representações éticas e políticas". A busca de todos os elementos que permitissem à inserção ao mundo civilizado: sentimento de patriotismo, dever comum como um valor a ser perseguido, representações da natureza tropical, elaboração de um imaginário e de uma história acerca das origens, a busca de uma aparência branca. Em contraposição, os elementos que não se ajustassem a tal imagem "seriam levados de roldão pelo progresso, ou passariam a ser mantidos e vistos como exóticos, no sentido de não civilizados” (NAXARA, 2000).

No século XIX, duas propostas apresentavam explicações e auxiliavam a elaboração representações para o Brasil. Uma perspectiva romântica voltada para a busca das origens e dos mitos e para a formação de uma história pautada no passado, que considerasse tanto o português quanto o selvagem e o negro em plano secundário. E também um registro cientificista, no qual a sensibilidade romântica se faz presente, propondo o conhecimento da natureza e do povo a partir de princípios regidos pela ciência e de acordo com os cânones estabelecidos. 


\section{Referências Bibliográficas:}

BARREIRO, José Carlos. Imaginário e viajantes no Brasil do século XIX: cultura e cotidiano, tradição e resistência. São Paulo: Editora da UNESP, 2002.

BELUZZO, Ana Maria. A propósito d'O Brasil dos Viajantes. Revista Usp, São Paulo (30):8-19, jun./ago. 1996.

BURKE, Edmund. Uma investigação filosófica sobre a origem de nossas idéias do sublime e do belo. Campins/SP: Papirus, 1993.

KANT, Emmanuel. Observações sobre o sentimento do belo e do sublime. Campinas/SP: Papirus, 1993.

LEITE, Ilka Boaventura. Antropologia da Viagem - Escravos e Libertos em Minas Gerais no século XIX. Belo Horizonte: Editora UFMG, 1996.

LOBO, Eulália Maria Lahmeyer. Viagem e viajantes: o remoto, o desconhecido e o maravilhoso. In: Viagens e viajantes, almocraves, bandeirantes, tropeiros e navegantes. III Colóquio Luso-Brasileiro,v. 1 (Anais). Vânia Leite Fróes (Coord. Geral). Niterói: Scriptorium, Laboratório de Estudos Medieval e Ibéricos/UFF, IHGB, UNIOESTE, ANPUH, 1998, p. 191-195.

MARTINS, Carlos (Org.). Revelando um acervo. São Paulo: Bei Comunicações, 2000.

PINTO, Olivério Mário Oliveira. Explorações Científicas. In: HOLANDA, Sérgio Buarque de. História Geral da Civilização Brasileira. Tomo 1: A Época Colonial, 2. ${ }^{\circ}$ vol. Administração, Economia, Sociedade. São Paulo: Difel, 1985.

NAXARA, Márcia Regina Capelari. Natureza e Civilização: sensibilidades românticas em representações do Brasil no século XIX. In: BRESCIANI, Stella; NAXARA, Márcia (Org.) Memória e (Res)sentimento — Indagações sobre uma questão sensível. Campinas/SP: Editora da Unicamp, 2000.

SILVA, Wilton Carlos Lima da. As terras inventadas - Discurso e natureza em Jean de Léry, André João Antonil e Richard Francis Burton. São Paulo: Editora da UNESP, 2003.

RIBON, Michel. A arte e a natureza. São Paulo: Papirus Editora, 1991.

SCHWARCZ, Lilia Moritz. Viajantes em meio ao Império das festas. Seminário Festas: Cultura e Sociabilidade na América Portuguesa. São Paulo, USP, 06-11 de setembro de 1999. 